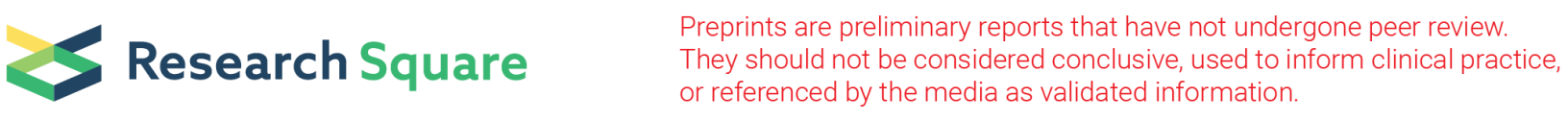

\title{
Designing an Optimization Model for Green Closed-Loop Supply Chain Network of Heavy Tire by Considering Economic Pricing under Uncertainty
}

Javad Amirian

Islamic Azad University Aliabad Katoul Branch

hossein amoozadkhalili ( $\sim$ amoozad92@yahoo.com )

Islamic Azad University, Nowshahr Branch https://orcid.org/0000-0001-7222-2233

Ahmad Mehrabian

Islamic Azad University Aliabad Katoul Branch

\section{Research Article}

Keywords: Uncertain fuzzy, Closed-looped supply chain, Environmental criterion, Pricing, Case study in the field of heavy tire, $\varepsilon$-constraint, Independent two-sample t-test.

Posted Date: February 7th, 2022

DOI: https://doi.org/10.21203/rs.3.rs-1241751/v1

License: @ (i) This work is licensed under a Creative Commons Attribution 4.0 International License. Read Full License

Version of Record: A version of this preprint was published at Environmental Science and Pollution Research on March 12th, 2022. See the published version at https://doi.org/10.1007/s11356-022-19578-0. 


\section{Abstract}

The conditions of global competition and environmental sensitivities have made organizations and factories to collect returned products. In such a way that these organizations have tried rehabilitate, recycle or destroy these products in order to protect the environment. This paper propose a mathematical model for the green closed-loop supply chain network of heavy tire by considering the economic pricing of its products under conditions of uncertainty, which economically determines the price and leads to more profitability. In addition, the relevant model is a two-objective fuzzy model, the first objective of which is to minimize costs and maximize profits and the second objective is to minimize environmental issues. The proposed model can also determine the optimal location of each center based on potential locations, the optimal amount of production, distribution, collection, recycling, as well as the reproduction of products. The $\varepsilon$-constraint method is used to solve the model with two objective functions; this method ensures strong Pareto optimal answers and prevents weak Pareto answers. Independent two-sample t-test is used to verify the results of certain and uncertain models in the studied model. In order to evaluate the effectiveness and profitability of the proposed method, a case study in the field of heavy tires is finally used, through which very useful results are obtained.

\section{Introduction}

The emissions of greenhouse gas causes more concern in the world due to the Paris Climate Agreement with the announcement of carbon emission targets by various countries for reducing global climate change. Industry and supply chain are the main sources of carbon emissions and pollution. Therefore, manufacturing companies have realized the importance of adopting environmentally friendly supply chain management practices and implement such programs in their business operations (Kumar et al. 2020). In this regard, discarded tires lead to increased water pollution, air pollution, $\mathrm{CO} 2$ emissions, risk to human health and economic losses. Tire retreading can reduce the demand for natural and energy resources to produce new tires by increasing the service life of the tire. Tire companies did not retread the tire due to lack of government commitment and sufficient profits (Saxena et al. 2018). In addition, the removal of huge amounts of tire waste around the world is now an economic and environmental issue. The annual production of 4.5 million tons of tires in Europe, 5.2 million tons in the United States, 1.2 million tons in Japan, 5.2 million tons in China and 0.9 million tons in India represent $88 \%$ of total tire production worldwide. Also, tire disposal has become a serious problem in the environment over the past decades. Environmental awareness has significantly increased exploration for the recycling of discarded tires to be environmentally friendly and economically viable (Jeguirim and Limousy 2017; Labaki and Jeguirim 2017). For this purpose, one of the things that can be done to reproduce these products, which is both economically and environmentally beneficial for the environment, is to consider a closed-loop supply chain in the field of tire reproduction so that these tires can be collected. In this regard, the following articles have addressed this issue.

Kumar et al. (2020) used a model for designing a sustainable Greenfield tire retreading supply network and group decision-making to combine economic, maximum profit, coverage, and capacity flexibility, carbon cost as an environmental dimension, and social benefit index as a social dimension. To solve the proposed model, a fuzzy multi-objective uncertainty method was used. Finally, numerical experiments provided important information for industry and government professionals. Tehrani and Gupta (2021), presented their study with the aim of designing and developing a stable multi-purpose network, multi-product, multi-step, multi-cycle, multi-capacity, green closed-loop under combined uncertainty. Demand uncertainty as well as fuzzy-based uncertainty regarding rate of return, rate of retread, rate of recycling, supply, and production costs were considered in the problem. They proposed a stable fuzzy random programming approach using probabilistic distributions. Kumar et al. (2020) proposed a strategic planning model for tire reconstruction under conditions of uncertainty and group decision-making for an adjustable supply chain to integrate the trade economy with carbon tax policy. To solve the proposed model, they used a fuzzy multi-objective method with a combination of different techniques.

It should be noted that, there are different methods for collecting products such as dumping, retread these products, etc., so a suitable method must be adopted in this chain to reduce collection costs, as well as being able to increase the revenue of this chain. The closedloop supply chain also includes decisions that involve both forward and backward. Decisions that start with the supply of raw materials and continue to the end customer include the forward supply chain. The backward supply chain also includes collection, reproduction, recycling, and access activities (Wei and Zhao 2013; Zhang 2006). Most manufacturers, such as Xerox, Hewlett-Packard, and IBM, use production and backward supply chain network (Chen and Chang 2012; Atasu et al. 2010; Choi et al 2013; Ferguson and Toktay 2004; Karakayali et al. 2007). For example, Ford saved $\$ 180,000$ in 1996 by using cartridge disposal (Wei et al. 2015). In addition, the company earned \$1.2 million in costs from 1991 to 1997 by reproducing and collecting 332,000 cartridges (Wei et al. 2015; Gutowski et al. 2011; Qiang et al. 2013). It should be noted that the purpose of most of the literature in the field of closed-loop supply chain has been on certain terms. It should be noted that the products to be collected in these chains make decisions in the model. These variables include the amount of recycled materials, the number of production centers, and the price of returned products (Üster et al. 2007 ; Listeş 2007). Thus, the dynamic and complex nature of the supply chain creates many uncertainties in the supply chain that cause the entire supply chain to 
change (Klibi et al. 2010; Dekker et al. 2013). In their paper, Leung et al. (2007) found that it is more difficult to estimate and control the quality and quantity of returned products in the supply chain, so uncertainty in the backward supply chain is much more important. For this reason, this type of uncertainty causes articles to consider this type of uncertainty in the backward supply chain.

Given the above discussion, the motivation for this paper is to consider a mathematical model for the green closed-loop supply chain network of heavy tire by considering the economic pricing of these products under uncertainty conditions. Finally, the innovations that distinguish this research from other researches and can enrich the literature in this field are as follows:

- Design of a multi-objective model in the green closed-loop supply chain of heavy tire, taking into account the economic pricing of reproduced products using proper collection of tires, considering an uncertainty fuzzy to de fuzzy the uncertainty parameters.

- Considering the environmental issue as a new target function because the reproduction of tires causes environmental pollution.

- None of the tire articles considered competition in their supply chain network. While we have included price factor in the relevant modeling.

- Simultaneous consideration of forward and backward decisions in the heavy tire supply chain network

- To solve the model of two objective-functions, the $\varepsilon$-constraint method is used; this method ensures strong Pareto optimal answers and prevents weak Pareto answers. In addition, an independent two-sample t-test is used to verify and validate the results of the certain and uncertain model in the model.

- Finally, to evaluate the effectiveness and usefulness of the proposed method, a case study in the field of heavy tires is conducted and useful management results are obtained for decision makers in this field.

Finally, the present article is planned as follows. In the next section, we will state the problem and model the assumptions. In section 3 , a fuzzy model for controlling the uncertainty of problem data will be presented. Section 4 explains and implements the solution method. In Section 5 , a case study will be used to validate the proposed model. In Section 6 , the numerical and managerial results will be presented and explained. Finally, general conclusions and suggestions for future research are provided.

\section{Problem Statement}

This paper presents a green closed-loop tire supply chain model. The relevant model is two-objective fuzzy model, the first objective is to minimize costs and maximize profits and the second objective is to minimize environmental issues in the chain. The components of this model include suppliers, manufacturers, distributors, product collectors, reproduction centers and recycling centers. In the considered green supply chain network, recycling and product collection centers are responsible for product collection referring them to recycling or reproduction centers or to destroy them if not repairable. In addition, it is possible to develop production and distribution centers under the name of new distribution centers and new production centers. One of the most important decisions obtained from the current model is to determine the optimal location of each component based on the potential locations and also to determine the optimal amount of production, distribution, collection, recycling and reproduction of the product. The following schematic figure is provided for further specification of the model.

In the above figure, the manufacturer receives the raw material from the supplier and sells it to distribution centers. There is a connection between distribution centers, collection centers, reproduction and recycling centers, while recycling centers have the possibility to yield revenue.

\subsection{Assumptions}

1. Potential locations for production, distribution, reproduction and recycling centers are determined in advance.

2. The capacity of supply, distribution, reproduction, recycling and disposal is limited.

3. The rates of return, recycling, and reproduction are uncertain.

4. The costs of raw material supply and production are uncertain.

5. Market demand (customers) is uncertain.

6. Only one transportation model takes place in this network (for example, only road transportation).

7. There is a fee considered for collecting used tires from each market. This cost encourages the end consumer to deliver the used tire to the retailer, and also encourages the retailer to receive and deliver used tires to collection centers. 
8. The market demand for the new tire must be satisfied, otherwise the shortage fee will be applied, but the satisfaction of the product demand in Retread is optional.

9. Transport companies buy the tires they need directly from distribution centers and transport them to reproduction centers for reproduction.

\section{Subscripts}

\begin{tabular}{|cl|}
\hline $\boldsymbol{i}$ & Set of potential locations \\
\hline$j$ & Set of supplier centers \\
\hline$k$ & Production centers \\
\hline$I$ & New manufacturing centers \\
\hline$m$ & Distribution Centers \\
\hline$n$ & New distribution centers \\
\hline$o$ & Product collection centers \\
\hline$p$ & Reproduction centers \\
\hline$q$ & Recycling centers \\
\hline$r$ & Set of various products \\
\hline
\end{tabular}

Parameters 


\begin{tabular}{|c|c|}
\hline$\tilde{R} \tilde{S} C_{j}$ & j Cost of raw materials from the supplier \\
\hline FROC $_{r}$ & p Fixed cost of ordering for the product \\
\hline$V_{R O C}$ & r Variable cost of product purchase \\
\hline$\tilde{P S C_{k r}}$ & $\mathrm{r}$ Production cost product, $\mathrm{k}$ production center \\
\hline$F C M_{k}$ & $\mathrm{k}$ Cost of construction of production center \\
\hline$F C M M_{m}$ & $\mathrm{~m}$ Cost of construction of distribution centers \\
\hline$D C M_{1}$ & I Cost of developing a new production center \\
\hline$D C M N_{n}$ & $\mathrm{n}$ Cost of developing a new distribution center \\
\hline$F C O_{O}$ & o Cost of construction of collection centers \\
\hline $\mathrm{CCO}_{\mathrm{O}}$ & O Collection fee of collection center \\
\hline$F C L_{1}$ & I Cost of construction of reproduction centers \\
\hline$F C Q_{q}$ & Cost of construction of recycling centers \\
\hline$T C$ & Total network flow costs \\
\hline$R I_{r}$ & $r$ Revenue from resale of the product \\
\hline$R C I_{r}$ & r Revenue from product recycling \\
\hline$R U I_{r}$ & $r$ Income from sales to the market for reuse of the product \\
\hline$M I_{r}$ & $r$ Revenue from the sale of product to the market for energy recovery \\
\hline$P O P K_{k}$ & $\mathrm{~K}$ The amount of pollution produced by the factory \\
\hline$P O P Q_{q}$ & Q The amount of pollution produced by the recycling center \\
\hline$P O P P_{p}$ & P The amount of pollution produced by the reproduction center \\
\hline$C O N P_{m p}$ & $\mathrm{~m}$ The amount of fuel consumption transported from the distribution center to the reproduction centers $p$ \\
\hline $\mathrm{POPO}_{\mathrm{o}}$ & o The amount of pollution caused by the destruction or burning of tires used by the product collection center \\
\hline$C A P J_{j}$ & J Supplier capacity \\
\hline$C A P K_{k}$ & K Manufacturer capacity \\
\hline$C A P M_{m}$ & m Distributor capacity \\
\hline $\mathrm{CAPO}_{\mathrm{o}}$ & O Capacity of the product collection center \\
\hline$C A P P_{p}$ & P Capacity of the reproduction center \\
\hline$C A P Q_{q}$ & Q Recycling center capacity \\
\hline$C A P L_{1}$ & L Capacity of new production center \\
\hline$C A P N_{n}$ & $\mathrm{n}$ Capacity of the new distribution center \\
\hline$\tilde{D E} M_{k r}$ & $\mathrm{r}$ The amount of customer demand for a new product from the manufacturer $\mathrm{K}$ \\
\hline
\end{tabular}




\begin{tabular}{|ll|}
\hline$\tilde{R} \tilde{S} C_{j}$ & j Cost of raw materials from the supplier \\
\hline$\tilde{D E M P}$ & Customer demand for the re-produced product $r$ from the manufacturer $\mathrm{p}$ \\
\hline $\operatorname{DefC}_{k r}$ & $\mathrm{r}$ Shortage cost for new product from manufacturer $\mathrm{k}$ \\
\hline$T C M P_{M P}$ & Cost of transporting materials from M distribution centers to $\mathrm{P}$ reproduction centers \\
\hline
\end{tabular}

\section{Decision variables}

\begin{tabular}{|c|c|}
\hline$X J_{j}$ & If supplier $j$ is selected to supply the raw materials required for the tire 1 and otherwise zero \\
\hline$X K_{k i}$ & If the production center $\mathrm{k}$ is constructed in place $\mathrm{i} 1$ and otherwise zero \\
\hline$Y K_{\text {kir }}$ & Production rate $\mathrm{r}$ by production center $\mathrm{k}$ in place $\mathrm{i}$ \\
\hline$X M_{m i}$ & If the distribution center $\mathrm{m}$ is located at location $\mathrm{i} 1$ and otherwise zero \\
\hline$Y M_{m i r}$ & The distribution rate of the distribution center $m$ at location $i$ for product $r$ \\
\hline$X O_{O i}$ & If the product collection center $\mathrm{o}$ is located in place i 1 and otherwise zero \\
\hline$Y \tilde{O}_{o i r}$ & Collection rate of product $r$ in product collection center $\mathrm{O}$ in place I \\
\hline$X P_{p i}$ & If the product reproduction center $p$ is located in place i 1 and otherwise zero \\
\hline$\tilde{P}_{p i r}$ & Product $r$ reproduction rate in reproduction center $\mathrm{p}$ in place $\mathrm{I}$ \\
\hline$X Q_{q i}$ & If the recycling center $q$ is constructed in place $i$ and otherwise zero \\
\hline$Y \tilde{Q}_{q i r}$ & Product $r$ recycling rate in recycling center $q$ in place $\mathrm{I}$ \\
\hline$X$ & The amount of total network flow between different levels of the supply chain \\
\hline$X L_{l i}$ & If a new production center $L$ is constructed at location i 1 and otherwise zero \\
\hline$X N_{n i}$ & If a new distribution center $\mathrm{n}$ is constructed at location I 1 and otherwise zero \\
\hline$Y L_{l i r}$ & $\mathrm{r}$ Production rate in new production center I in place $\mathrm{i}$ \\
\hline$Y N_{n i r}$ & Product $r$ distribution rate in distribution center $\mathrm{n}$ in place $\mathrm{i}$ \\
\hline$X D E F_{k r}$ & The shortage of commodity $\mathrm{K}$ for the product $\mathrm{r}$ \\
\hline$X T C M P_{M P r}$ & The flow of $r$ product from distribution centers $M$ to reproduction centers $P$ \\
\hline$X R I_{r}$ & Product $r$ resale price \\
\hline$X R C I_{r}$ & Product $r$ recycling value \\
\hline$X R U I_{r}$ & Market selling price for product $r$ reuse \\
\hline$X M I_{r}$ & The selling price of the product $r$ to the market for energy recovery \\
\hline
\end{tabular}

Furthermore, we address the objective functions of the problem, which include economic and environmental objective functions. The economic objective is to minimize the costs of the entire network, which are as follows: 
1) The cost of supplying raw materials, including the fixed cost of ordering and the variable cost of purchase. 2) The cost of construction and development of production centers. 3) The cost of construction and development of the distribution center. 4) The cost of constructing collection centers. 5) The cost of constructing new production centers. 6) The cost of constructing recycling centers. 7) Total network flow costs including the transportation of materials and products between two different levels of the supply chain.

The economic objective can also be presented as maximizing revenue:

1) Revenue from resale 2) Revenue from recycling 3) Revenue from resale to market for reuse 4) Revenue from resale to market for energy recovery

The objective functions and problem constraints are modeled in the following.

$$
\begin{aligned}
& \operatorname{maxz1}=R I_{r} X R I_{r}+R C L_{r} X R C L_{r}+R U I_{r} X R U I_{r}+M I_{r} X M I_{r}-\left[\sum_{j} \tilde{R S} C_{j} \cdot X J_{j}+\sum_{k} \tilde{P S C_{k}} \cdot Y K_{k i}\right. \\
& +\sum F C M_{k} X K_{k i}+\sum F C M M_{m} \cdot X M_{m i}+\sum D C M_{L} \cdot X L_{l i}+\sum D C M N_{n} \cdot X N_{n i}+\sum F C O_{o} \cdot X O_{o i}+\sum C C O_{o} Y O_{o i} \\
& \left.+\sum_{l}^{k} F C L_{1} X L_{l I}+\sum_{Q} F C Q_{q} \cdot X Q_{q i}+\sum_{k} D^{2} C_{k^{*}}^{l} X D E F_{k}+\sum_{m} \sum_{p}^{n} T C M P_{m p}\right]+T C+F R O C+V C O C \\
& \min z 2=\sum_{k} P O P K_{k} \cdot X K_{k i}+\sum_{q} P O P Q_{q} . X Q_{q i}+\sum_{p} P O P P_{p} \cdot X P_{p i}+\sum_{m} \sum_{p} C O N P_{m p} . X M_{m i}+\sum_{o} P O P o_{o} \cdot X O_{O i}
\end{aligned}
$$

$X J_{j} \leq 1 \forall j$

$X K_{k i} \leq 1 \forall k, i$

$\sum_{i}^{X K_{k i}}=1 \forall k$

$Y K_{k i r} \geq D E M_{k r} \forall k, i, r$

$Y K_{k i r} \leq C A P K_{k} \forall k, i, r$

$X M_{m i} \leq 1 \forall m, i$

$\sum_{i} X M_{m i}=1 \forall m$

$Y M_{m i} \leq C A P M_{m} \forall m, i$

$X O_{O i} \leq 1 \forall O, i$ (11)

$\sum_{i}^{X O} O_{O i}=1 \forall o$

$\tilde{Y O}_{o i} \leq C A P M_{m} \forall o, i, m$

$X P_{p i} \leq 1 \forall p, i \quad(14)$

$\sum_{i}^{X P_{p i}}=1 \forall p$

$\tilde{Y P}_{p i} \leq C A P P_{p} \forall p, i$

$X Q_{q i} \leq 1 \forall q, i \quad(17)$

$\sum_{i} X Q_{q i}=1 \forall q$ (18)

$\sim$

$Y Q_{q i r} \leq C A P Q_{q} \forall q, i, r$

$X=\sum \sum_{r} \sum_{m} X T C M P_{m p r}$ 
$X L_{l i} \leq 1 \forall l, i \quad(21)$

$\sum X L_{l i}=1 \forall l(22)$

$Y L_{l i r} \leq C A P L_{l} \forall l, i, r$ (23)

$X N_{n i} \leq 1 \forall n, i \quad(24)$

$\sum_{i} X N_{n i}=1 \forall n(25)$

$Y N_{n i r} \leq C A P N_{n} \forall n, i, r$ (26)

$X D E F_{k}=D E M_{k r}+D E M P_{p r}-Y K_{k i r} \forall k, i, r, p$

$\sum_{k} \sum_{i} Y K_{k i r}=\sum_{m} \sum_{i} Y M_{\operatorname{mir}} \forall r$ (28)

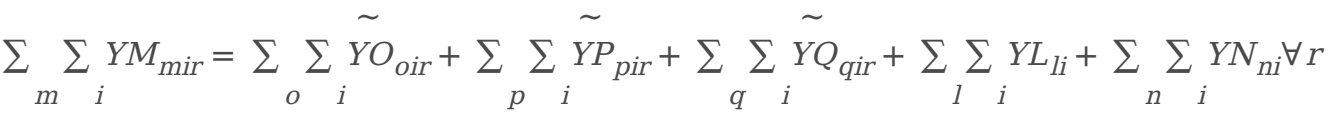

Equation 1 seeks to maximize profits or minimize costs. Revenues as well as expenses are separately presented in the previous section. Equation 2 seeks to minimize environmental issues. Equation 3 states that it is possible to supply from each supplier up to one time. Equation 4 indicates that each plant is established at most once. Equation 5 shows that the total location of a factory equals one. Equation 6 shows that the amount of production for each factory should be more than the amount of demand for that factory. Equation 7 shows that the output of each plant should not exceed the capacity of that plant. Equation 8 shows that each distribution center is established at most once. Equation 9 states that a distribution center can only be established in one potential location. Equation 10 shows that the total amount of distribution for each distribution center cannot exceed the capacity of that distribution center. Equation 11 shows that each product collection center can only be constructed once.

Equation 12 shows that there is only one place for each product collection center. Equation 13 states that the total amount of product collected by each collection center cannot exceed its capacity. Equation 14 shows that each reproduction center can only be constructed once. Equation 15 shows that each reproduction center is constructed in only one place. Equation 16 shows that the total amount produced by each reproduction center could not exceed its capacity. Equation 17 shows that each recycling center can be established only once. Equation 18 shows that only one site is allocated for the construction of each recycling center. Equation 19 shows that the capacity of each recycling center is limited. Equation 20 states that the total network flow is equal to the total amount of transport from distribution centers to reproduction centers. Equation 21 shows that each new production center can be constructed only once. Equation 22 shows that there is only one location for each production center. Equation 23 indicates that the total amount of production for the reproduction centers should be less than its capacity. Equation 24 shows that each new distribution center can only be constructed in one location. Equation 25 shows that the total potential locations for each new distribution center are just one location. Equation 26 indicates the capacity limit of each new distribution center. Equation 27 indicates the degree of shortage. Equation 28 shows that the total amount of production should be the same as the amount of collection. Equation 29 indicates the constraint of closed-loop supply chain.

\section{Fuzzy Modeling Of Problem}

In the proposed problem, some parameters have a fuzzy value. The method of Khamiz et al. (2007) was used to convert the uncertain fuzzy model to certain model This method uses the concept of mathematical expectation and the expected range of fuzzy numbers to defuzzify a possibility model. This method while maintaining the lineability of the model, does not increase the number of objective functions and unequal constraints.

Assuming that $\tilde{c}=\left(c^{p}, c^{m}, c^{O}\right)$ is a triangular fuzzy number, then the expected range and mathematical expectation of the fuzzy number $\tilde{C}$ are equal to

$$
\begin{aligned}
& E I(\tilde{c})=\left[E_{1}^{c}, E_{2}^{c}\right]=\left[\frac{1}{2}\left(c^{p}+c^{m}\right), \frac{1}{2}\left(c^{m}+c^{o}\right)\right] \\
& E V(\tilde{c})=\frac{E_{1}^{c}+E_{2}^{c}}{2}=\frac{c^{p}+2 c^{m}, c^{o}}{4}
\end{aligned}
$$


Based on the above relation, the relations that have fuzzy parameters can be rewritten as follows, and thus the model is defuzzified.

$\max z 1=R I_{r} X R I_{r}+R C L_{r} X R C L_{r}+R U I_{r} X R U I_{r}+M I_{r} X M I_{r}-\left[\sum_{j}^{\frac{R S C 1_{j}+2 R S C 2_{j}+R S C 3_{j}}{4}} \cdot X J_{j}+\sum_{k} \frac{P C S 1_{k}+2 P S C 2_{k}+P S C 3_{k}}{4} \cdot Y K_{k i}\right.$

$+\sum F C M_{k} X K_{k i} \cdot+\sum F C M_{m} \cdot X M_{m i}+\sum D C M_{L} \cdot X L_{l i}+\sum D C M N_{n} . X N_{n i}+\sum F C O_{o} . X O_{o i}+\sum C C O_{o} Y O_{o i}$

$\left.+\sum_{l}^{k_{F C L} X L_{I I}}+\sum_{Q} F C^{\mathrm{R}} Q_{q} . X Q_{q i}+\sum_{k} \operatorname{DefC}_{k^{*}}^{l} X D E F_{k}+\sum_{m} \sum_{p}^{n^{n}} T C M P_{m p}\right]+T C+F R O C+V C O C$

$X D E F_{k}=\frac{D E M 1_{k r}+2 D E M 2_{k r}+D E M 3_{k r}}{4}+\frac{D E M P 1_{k r}+2 D E M P 2_{k r}+D E M P 3_{k r}}{4}-Y K_{k i r}$

$Y K_{k i r} \geq \frac{D E M 1_{k r}+2 D E M 2_{k r}+D E M 3_{k r}}{4}$

The above relations represent the defuzzified form of relations 1 as a function of the objective of the problem as well as relations (6) and (27). Figures are considered as triangular fuzzy.

\section{Solution Method}

The solution method in the present study includes the exact method. This method includes the Epsilon constraint algorithm. This section describes this algorithm.

\subsection{Epsilon constraint algorithm}

The present problem is solved using the Epsilon constraint method. The problem is solved in such a way that the first objective is considered as the main objective and the other objectives are limited to the upper limit of Epsilon and are applied in the problem constraints. In this case, based on the Epsilon method, the following single-objective model constraint is obtained.

$\operatorname{minf} 1(\mathrm{x})$

$\mathrm{fi}(\mathrm{x}) \leq \mathrm{e}_{\mathrm{i}}$

$\mathrm{x} \in \mathrm{X}$ (35)

Where the first objective is considered as the main objective and the objectives second to nth are limited to maximum value of ei. In the Epsilon constraint method, by changing the values of ei, different answers are obtained that may not be effective. By modifying and completing the above model, the mentioned problem can be solved, which is known as the developed epsilon constraint method. In this method, the previous relation is rewritten in this way.

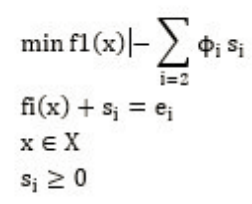

Where $s_{i}$ is negative auxiliary variable and $\Phi_{i}$ is a parameter for normalizing objectives. By obtaining the outcome matrix of the problem objectives, several different values are selected by the lexicographic method, and the Pareto front is obtained in this way.

\section{Case Study}

Rubber is defined as a material that has elastic properties. So that its most important property is stretching, so that sometimes it stretches up to 60 times its original length. Natural rubber loses heat when stretched and absorbs heat when it returns. It should be noted that the properties of the raw polymer do not represent the composition and properties of the rubber in the final state because to achieve some of the desired properties for a tire we need a long process and this time for the process increases the price of rubber. Rubber generally has a low modulus of elasticity and is, therefore, able to withstand deformation up to more than one thousand percent. The rubber industry, after the discovery of how to vulcanize it (in 1839), has now emerged as a very important economic industry, and many rubber parts and products can be seen in the market, including truck tires and other equipment. Transportation, hoses, conveyor belts, rubber mats and plates, V-shaped straps, heel and shoe beds, rubber sponges and many other parts. In 1881, the inflatable bicycle tire was invented by the 
English inventor (Dunlop). In 1912, Diamond Company discovered that adding soot to a rubber compound improved its abrasion resistance and other physical properties.

\section{The Results Of The Model And The Collection And Estimation Of Data 6.1. Results of model solving}

In this section, the proposed model is solved using Gomez software and Epsilon constraint method and in different dimensions and its results are presented. The results are presented in the form of calculating continuous price variables of product prices, while Pareto diagram, which is suitable for two-objective problems, is also presented below.

Table 1

Product selling price in different modes

\begin{tabular}{|lcccc|}
\hline Product & $\mathbf{1}$ & $\mathbf{2}$ & $\mathbf{3}$ & $\mathbf{4}$ \\
\hline Product resale price & 900 & 970 & 950 & 870 \\
\hline Product recycling value & 300 & 320 & 330 & 290 \\
\hline Market selling price for product reuse & 440 & 560 & 480 & 510 \\
\hline The selling price of the product to the market for energy recovery & 320 & 280 & 270 & 250 \\
\hline
\end{tabular}

In the Pareto chart obtained from the problem-solving data, the intersections of the two objective functions are shown and shown as follows.

As it can be seen, the optimal points obtained from the intersection of the two objective functions in this problem are obtained, which indicates an almost inverse relationship between the two objective functions of profit and environmental issues. Although in some parts of the chart we see the density of points, but in general we can see that increasing profits leads to reducing environmental benefits and vice versa.

\subsection{Comparison of results in definite and fuzzy situations}

Then, considering that some parameters of the model are fuzzy, so the definite and fuzzy states are considered as two separate states and we want to know what effect the uncertainty has on the model and its results.

As it can be seen, the results of problem solving in the definite and fuzzy states are somewhat different in the discussion of costs. In other words, the cost in the fuzzy state is higher than the definite state, which indicates that uncertainty can lead to increased costs in the supply chain.

In the above diagram, the issue of environmental issues is examined and it is shown that in the fuzzy situation, we see a worse situation in terms of environmental issues compared to the definite situation. Therefore, it can be said that uncertainty has led to an increase in environmental issues in the present issue. On the other hand, the results in the fuzzy state have more fluctuations than the definite state.

\subsection{Statistical analysis of uncertainty}

Next, an independent two-sample t-test is used to confirm the difference between the situation of uncertainty and uncertainty. The results for both objective functions are as follows.

Table 2

T-test to evaluate the significance of cost values.

\begin{tabular}{|llllllll|}
\hline $\begin{array}{l}\text { The significance } \\
\text { level }\end{array}$ & $\begin{array}{l}\text { Freedom } \\
\text { degree }\end{array}$ & $\begin{array}{l}\text { T } \\
\text { value }\end{array}$ & $\begin{array}{l}\text { Lower } \\
\text { limit }\end{array}$ & $\begin{array}{l}\text { Upper } \\
\text { limit }\end{array}$ & $\begin{array}{l}\text { Standard error } \\
\text { Mean }\end{array}$ & $\begin{array}{l}\text { Standard } \\
\text { Deviation }\end{array}$ & Mean \\
\hline 0.002 & 11 & -4.321 & -3.657 & -0.86656 & 0.47110 & 1.2261 & -1.6778 \\
\hline
\end{tabular}

T-test is run to check the significance of the differences. Of course, in some cases, by performing t-test or analysis of variance, we seek to see which group is superior to the other group. We do not have such a goal here and we just want to know if there is a significant difference between the state of certainty and uncertainty. Therefore, other than the level of significance, other statistics and coefficients are not important, and considering that the level of significance is close to zero, it can be said that there is a significant difference between the state of certainty and uncertainty in the present problem and uncertainty leads to worsening. Has been answered.

Page $10 / 19$ 
Table 3

T-test to evaluate the significance of the values of environmental issues.

\begin{tabular}{|llllllll|}
\hline $\begin{array}{l}\text { The significance } \\
\text { level }\end{array}$ & $\begin{array}{l}\text { Freedom } \\
\text { degree }\end{array}$ & $\begin{array}{l}\text { T value } \\
\text { velower }\end{array}$ & $\begin{array}{l}\text { Upper } \\
\text { limit }\end{array}$ & $\begin{array}{l}\text { Standard error } \\
\text { Mean }\end{array}$ & $\begin{array}{l}\text { Standard } \\
\text { deviation }\end{array}$ & Mean \\
\hline 0.002 & 11 & -4.321 & -3.657 & -0.86656 & 0.47110 & 1.2261 & -1.6778 \\
\hline
\end{tabular}

Conversely, the cost situation with respect to the significance level of 0.002 regarding the comparison of uncertainty and uncertainty can be said that there is a significant difference in $95 \%$ confidence level between certainty and uncertainty and therefore the uncertainty situation leads to change in the problem or improvement or deterioration of the answer. Therefore, the effect of uncertainty on the discussion of costs and environmental issues and the worsening of the answer is confirmed.

\subsection{Sensitivity analysis}

With the help of sensitivity analysis, it can be found that what changes in some important parameters that can be changed lead to a reaction by the model and in which direction the results are directed. Here 4 parameters of product demand from the distributor, demand for reproduction of goods, capacity of collection centers and capacity of recycling centers are analyzed. The last two parameters are related to environmental issues and the reason for examining them in this section is to pay attention to environmental issues.

As it can be seen in this section, increasing demand leads to increased environmental issues as well as increased profits. Naturally, with increasing demand, one can expect an increase in profits, but at the same time, one can expect an increase in environmental issues following an increase in production. In the following, we analyze the sensitivity of profit and environmental purpose according to changes in demand for the reproduced product.

With the increase in demand for the recycled product, we see an increase in profits and an increase in environmental issues, although in the end this increase seems to have stabilized and in fact we can say that the increase is done only in the early periods. In the following, the analysis of profit sensitivity and environmental objective function according to increasing the capacity of collection centers is presented.

Based on the above two diagrams, it can be seen that increasing the capacity of collection centers leads to a decrease in profits because the cost of construction of collection centers increases and naturally reduces profits. This shows that even an increase in collection revenue can not prevent a decrease in profits. But on environmental issues, there is no tangible change following the increase in the capacity of collection centers. In the following diagrams, we examine the changes in the profit objective function and environmental emissions according to increasing the capacity of recycling centers.

The above two diagrams show that increasing the capacity of recycling centers due to increasing revenue from the sale of recycled products can lead to increased profits. This income is enough to cover the construction costs of recycling centers. But at the same time, environmental issues will increase as the capacity of recycling centers increases.

\section{Conclusion}

In this research, a mathematical model for the green closed supply chain of heavy rubber has been used considering the economic pricing of these products under conditions of uncertainty. In addition, the model is fuzzy and has two objectives, the first goal is to maximize profits and the second goal is to minimize environmental emissions of the chain. After solving the model, Pareto analysis of the problem was run, which shows the inverse relationship between the two goals of profit and environmental issues. In addition, sensitivity analysis was performed for four parameters that indicated the sensitivity of the model to increasing the total demand and demand for recycled products, as well as the capacity of collection centers and recycling centers. The optimal points obtained from the intersection of the two objective functions in this issue indicate an almost inverse relationship between the two functions of the profit target and environmental issues, which increase the profit leading to a decrease in environmental benefits and vice versa. As it was observed, the results of solving the problem in the definite and fuzzy states are somewhat different in the discussion of costs. In other words, the cost in the fuzzy state is higher than the definite state, which indicates that uncertainty can lead to increased costs in the supply chain. Furthermore, the issue of environmental issues is examined and it is shown that in the fuzzy situation has a worse situation in terms of environmental issues compared to the definite situation. Thus, it can be said that uncertainty has led to an increase in environmental issues in the present issue. On the other hand, the results obtained in the fuzzy state have more fluctuations than the definite state. T-test was performed to evaluate the differences. Of course, in some cases, after performing t-test or analysis of variance, we seek to see which group is superior to the other group. It can be said that there is a significant difference between the situation of certainty and uncertainty in the present problem and uncertainty has led to a worse answer. This study is one of the new works in the field of reverse logistics optimization. Hence, it can be expanded in various ways that the literature can enrich it. For example, using resilience strategies for relevant modeling using a scenario- 
based mathematical model, providing an accurate algorithm to solve the heavy tire supply chain problem, using a combination of robust optimization methods, and planning to control data uncertainty.

\section{Ethical Approval}

\section{and Competing Interests}

- All authors have participated in (a) conception and design, or analysis and interpretation of the data; (b) drafting the article or revising it critically for important intellectual content; and (c) approval of the final version.

- This manuscript has not been submitted to, nor is under review at, another journal or other publishing venue and has not selfplagiarism

- The authors have no affiliation with any organization with a direct or indirect financial interest in the subject matter discussed in the manuscript

\section{Declarations}

\section{Ethical Approval and Competing Interests}

- All authors have participated in (a) conception and design, or analysis and interpretation of the data; (b) drafting the article or revising it critically for important intellectual content; and (c) approval of the final version.

- This manuscript has not been submitted to, nor is under review at, another journal or other publishing venue and has not selfplagiarism

- The authors have no affiliation with any organization with a direct or indirect financial interest in the subject matter discussed in the manuscript

\section{Consent to Participate and Consent to Publish}

Furthermore, we hereby transfer the unlimited rights of publication of the above-mentioned paper in whole to "Environmental science and pollution research". The corresponding author signs for and accepts responsibility for releasing this material on behalf of any and all coauthors. This agreement is to be signed by at least one of the authors who have obtained the assent of the co-author(s) where applicable. After submission of this agreement signed by the corresponding author, changes of authorship or in the order of the authors listed will not be accepted.

Yours Sincerely,

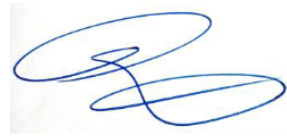

\section{Authors Contributions}

Javad Amirian: methodology; software; formal analysis; data curation; writing original draft; writing review and edit; visualization;

Hossein Amoozad Khalili: conceptualization, supervision, software, methodology; software; formal analysis; data curation; writing original draft; visualization;

Ahmad Mehrabian: methodology, validation; validation, writing review and edit;

\section{Declaration of interests}

The authors declare that they have no known competing financial interests or personal relationships that could have appeared to influence the work reported in this paper.

\section{Funding}

This research received no specific grant from any funding agency in the public, commercial, or not-for-profit sectors.

\section{Availability of data and materials}


The data that support the findings of this study are available from the corresponding author, , upon reasonable request

\section{References}

1. Atasu A, Guide Jr R, Van Wassenhove N (2010) So what if remanufacturing cannibalizes my new product sales? California Management Review. 52(2): p. 56-76.

2. Chen M, Chang I (2012) The co-opetitive strategy of a closed-loop supply chain with remanufacturing. Transportation Research Part E: Logistics and Transportation Review. 48(2): p. 387-400.

3. Choi M, Li Y, Xu L (2013) Channel leadership, performance and coordination in closed loop supply chains. International Journal of Production Economics. 146(1): p. 371-380.

4. Dekker R, Fleischmann M, Inderfurth K, van Wassenhove L (2013) Reverse logistics: quantitative models for closed-loop supply chains. Springer Science \& Business Media.

5. Ferguson M, Toktay B (2004) The effect of external competition on recovery strategies. Georgia Institute of Technology College of Business working paper.

6. Gutowski T, Sahni G, Boustani S, Graves S (2011) Remanufacturing and energy savings. Environmental science \& technology, 45(10), 4540-4547.

7. Jeguirim M, Limousy L (2017) Process engineering for pollution control and waste minimization, Springer.

8. Karakayali I, Emir-Farinas H, Akcali E (2007) An analysis of decentralized collection and processing of end-of-life products. Journal of Operations Management. 25(6): p. 1161-1183.

9. Klibi W, Martel A, Guitouni A (2010) The design of robust value-creating supply chain networks: a critical review. European Journal of Operational Research. 203(2): p. 283-293.

10. Kumar L, Jain P, Sharma A (2020) A fuzzy goal programme-based sustainable Greenfield supply network design for tyre retreading industry. The International Journal of Advanced Manufacturing Technology,. 108(9): p. 2855-2880.

11. Labaki M, Jeguirim M (2017) Thermochemical conversion of waste tyres-a review. Environmental Science and Pollution Research. 24(11): p. 9962-9992.

12. Leung C, Tsang O, Ng W, Wu Y (2007) A robust optimization model for multi-site production planning problem in an uncertain environment. European journal of operational research, 181(1), 224-238.

13. Listeş O (2007) A generic stochastic model for supply-and-return network design. Computers \& Operations Research. $34(2)$ : p. 417-442.

14. Qiang Q, Ke K, Anderson T, Dong J (2013) The closed-loop supply chain network with competition, distribution channel investment, and uncertainties. Omega, 41(2), 186-194.

15. Saxena K, Jain P, Sharma A (2018) A fuzzy goal programme with carbon tax policy for Brownfield Tyre remanufacturing strategic supply chain planning. Journal of Cleaner Production. 198: p. 737-753.

16. Saxena, Jain P, Sharma A (2018) Tactical supply chain planning for tyre remanufacturing considering carbon tax policy. The International Journal of Advanced Manufacturing Technology, 97(1): p. 1505-1528.

17. Tehrani M, Gupta M (2021) Designing a Sustainable Green Closed-Loop Supply Chain under Uncertainty and Various Capacity Levels. Logistics. 5(2): p. 20.

18. Üster H, Easwaran G, Akçali E, Çetinkaya S (2007) Benders decomposition with alternative multiple cuts for a multi-product closed-loop supply chain network design model. Naval research logistics (NRL), 54(8), 890-907.

19. Wei J, Govindan K, Li Y, Zhao J (2015) Pricing and collecting decisions in a closed-loop supply chain with symmetric and asymmetric information. Computers \& operations research, 54, 257-265.

20. Wei J, Zhao J (2013) Reverse channel decisions for a fuzzy closed-loop supply chain. Applied Mathematical Modelling. 37(3): p. 15021513.

21. Zhang D (2006) A network economic model for supply chain versus supply chain competition. Omega. 34(3): p. 283-295.

\section{Figures}




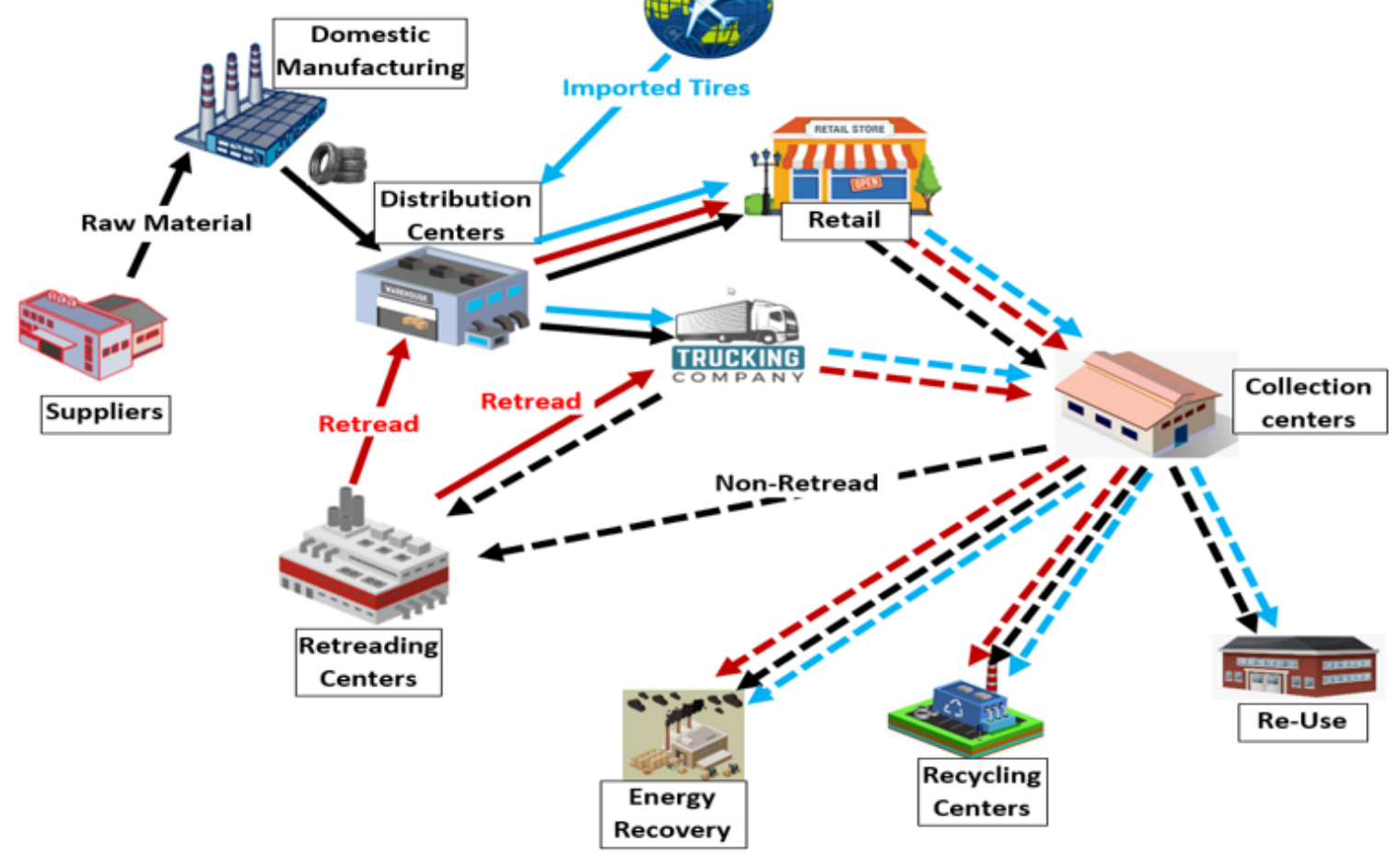

Figure 1

Schematic of the current research supply chain.

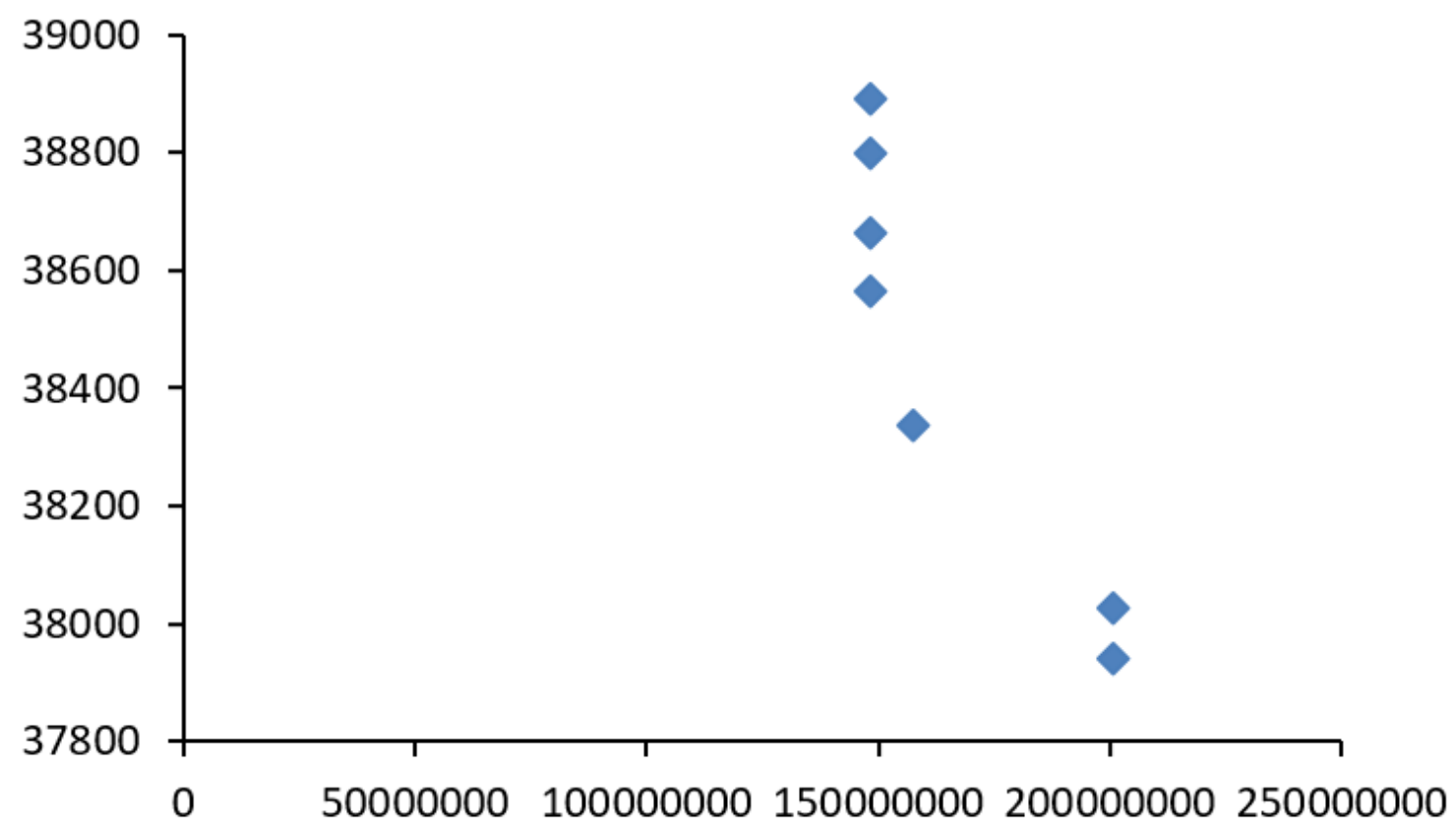

Figure 2

Pareto chart of the present problem 


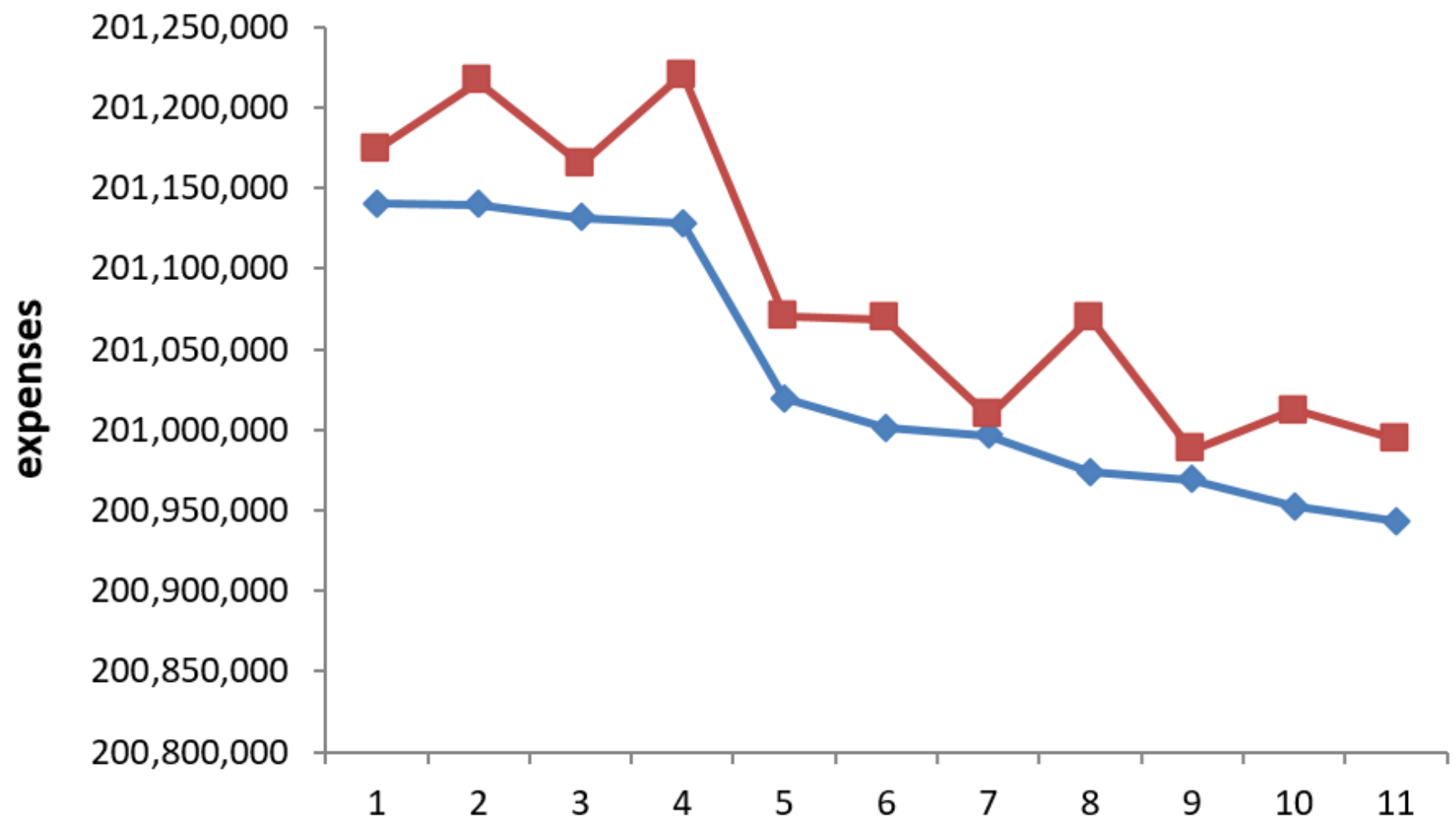

Figure 3

Comparison of definite and fuzzy situation in terms of costs.

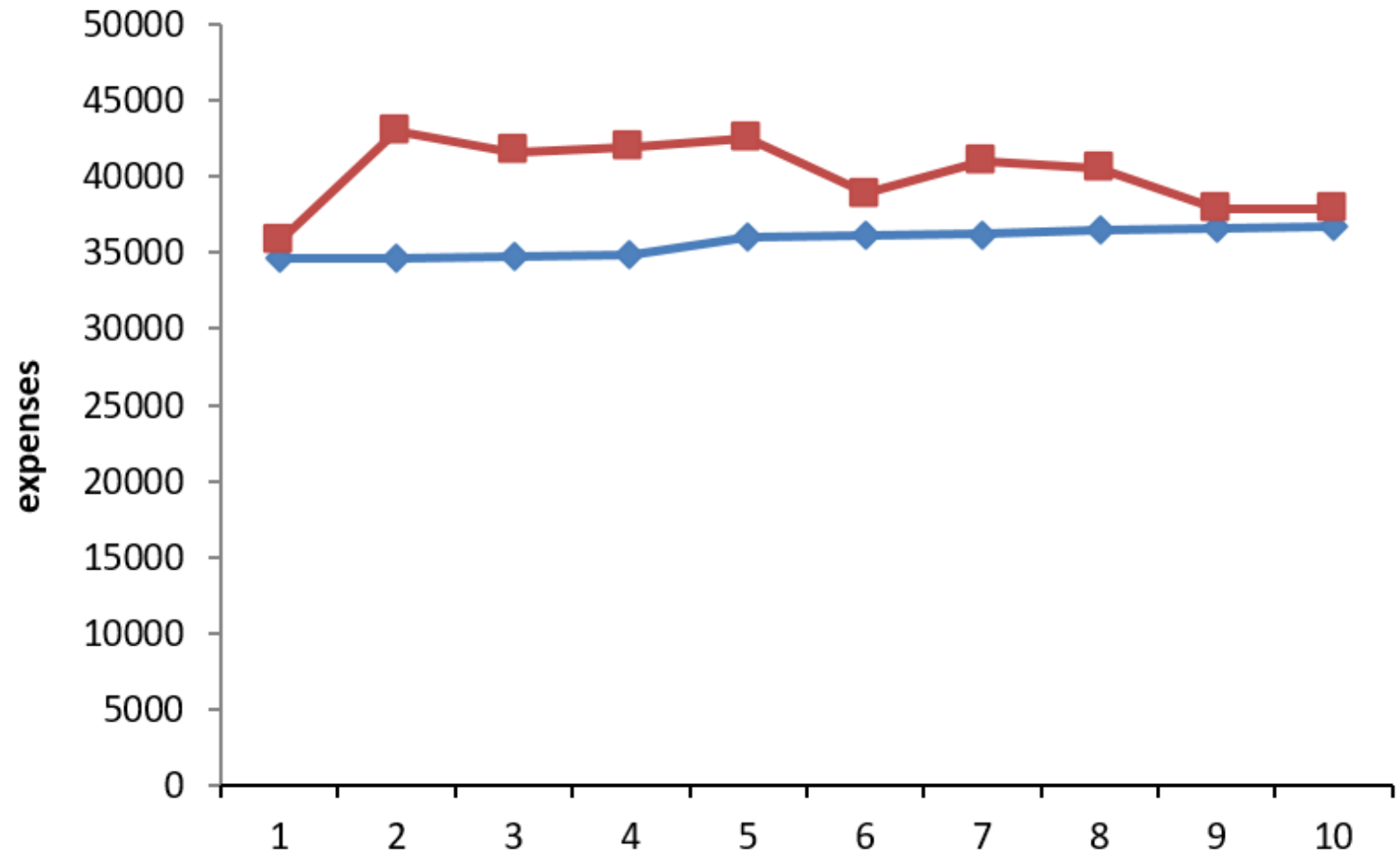

Figure 4

Comparison of definite and fuzzy situations regarding environmental issues. 


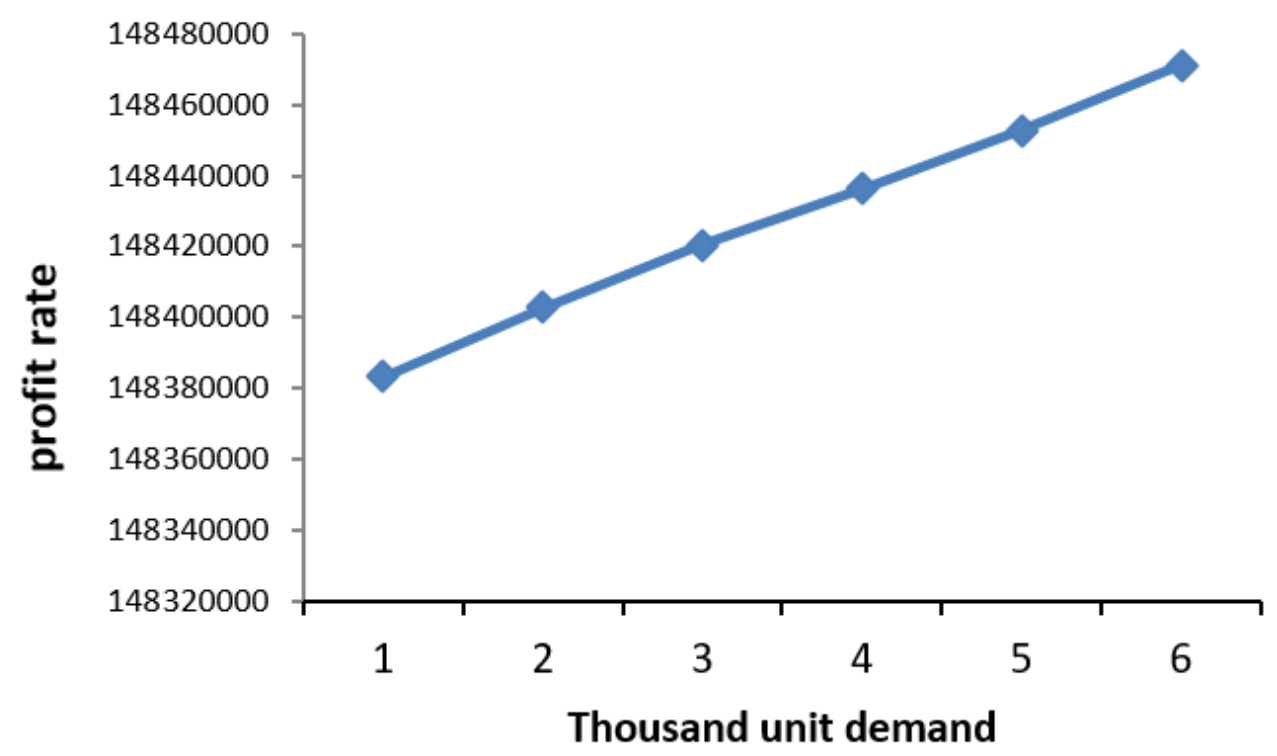

Figure 5

Analysis of profit sensitivity following increased demand.

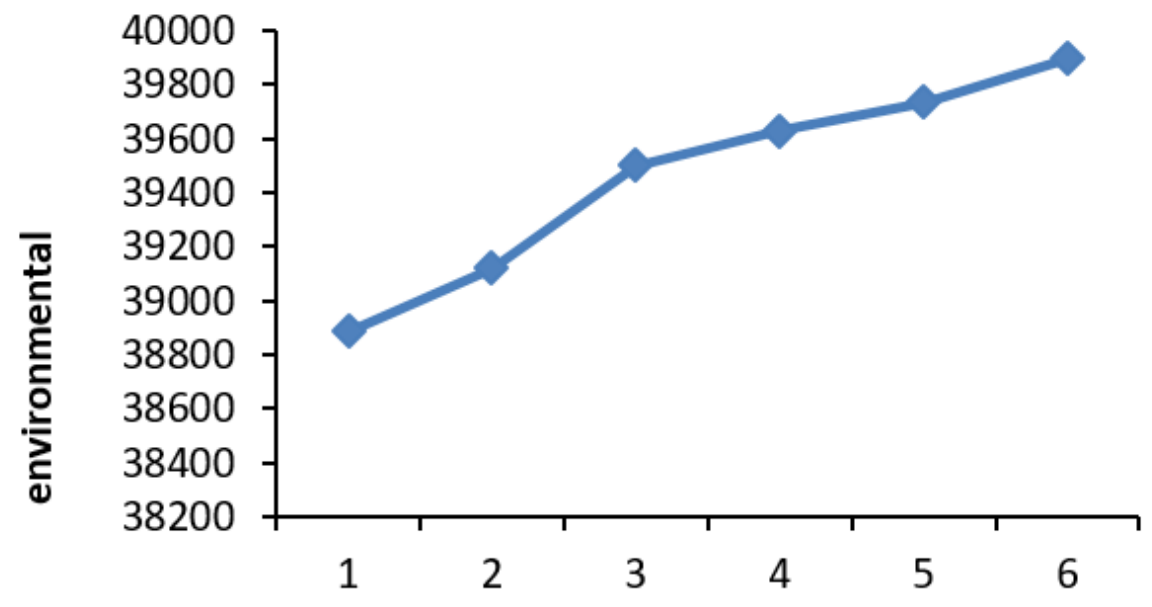

Thousand unit demand

Figure 6

Sensitivity analysis of environmental issues following increasing demand. 


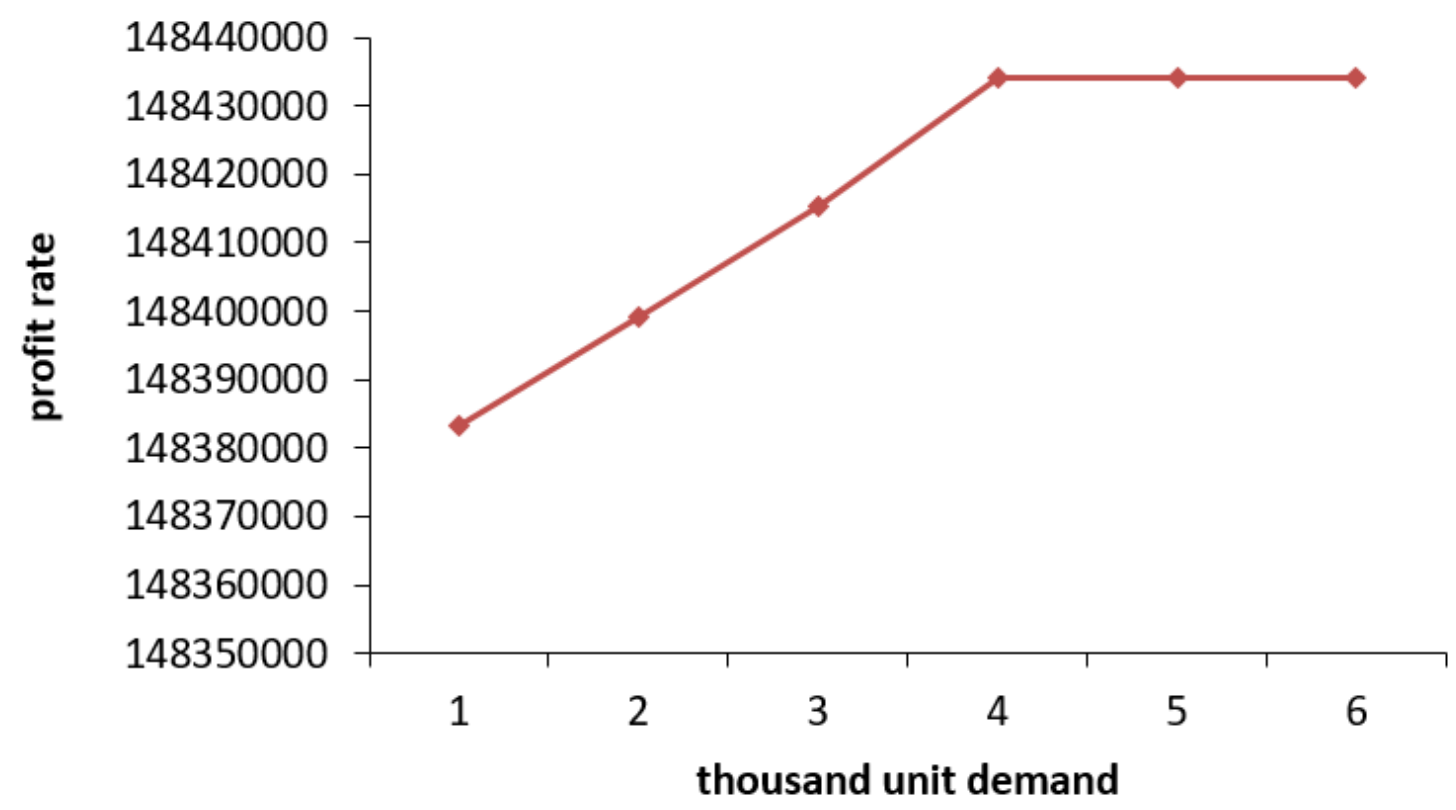

Figure 7

Profit sensitivity analysis following increased demand for the remanufactured product.

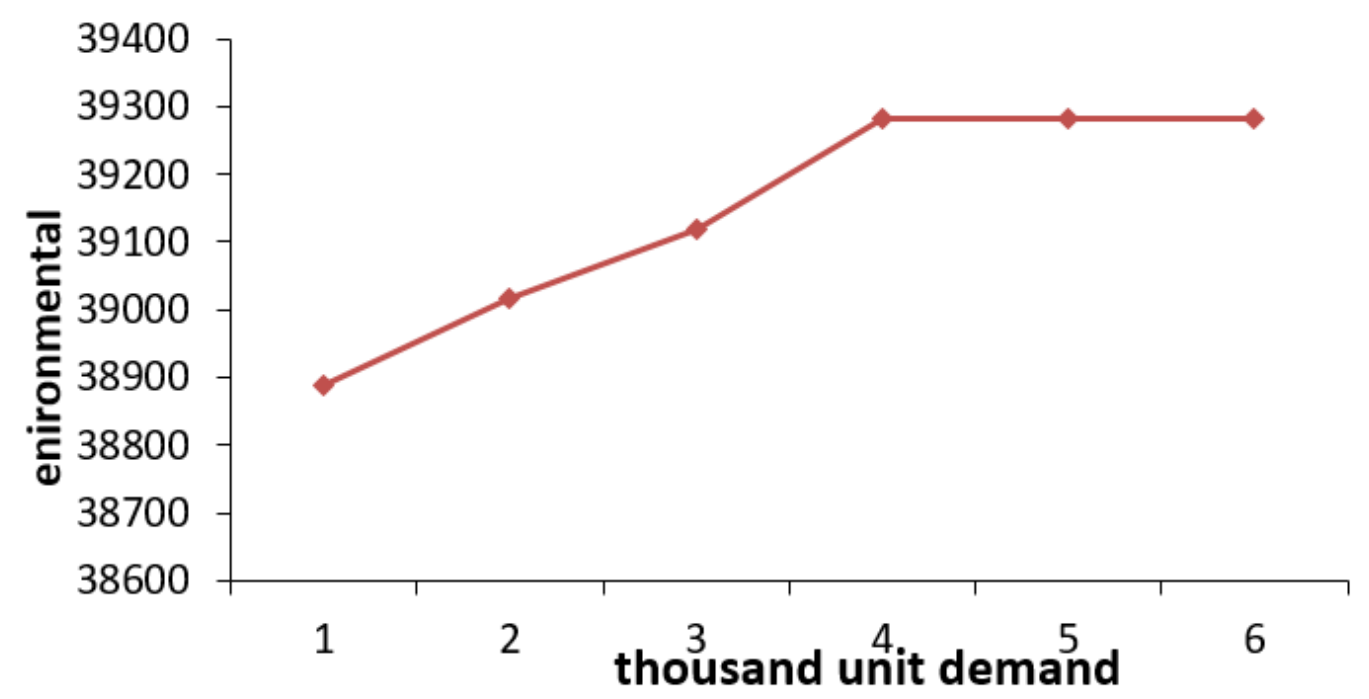

Figure 8

Environmental target analysis following the increase in demand for the reproduced product. 


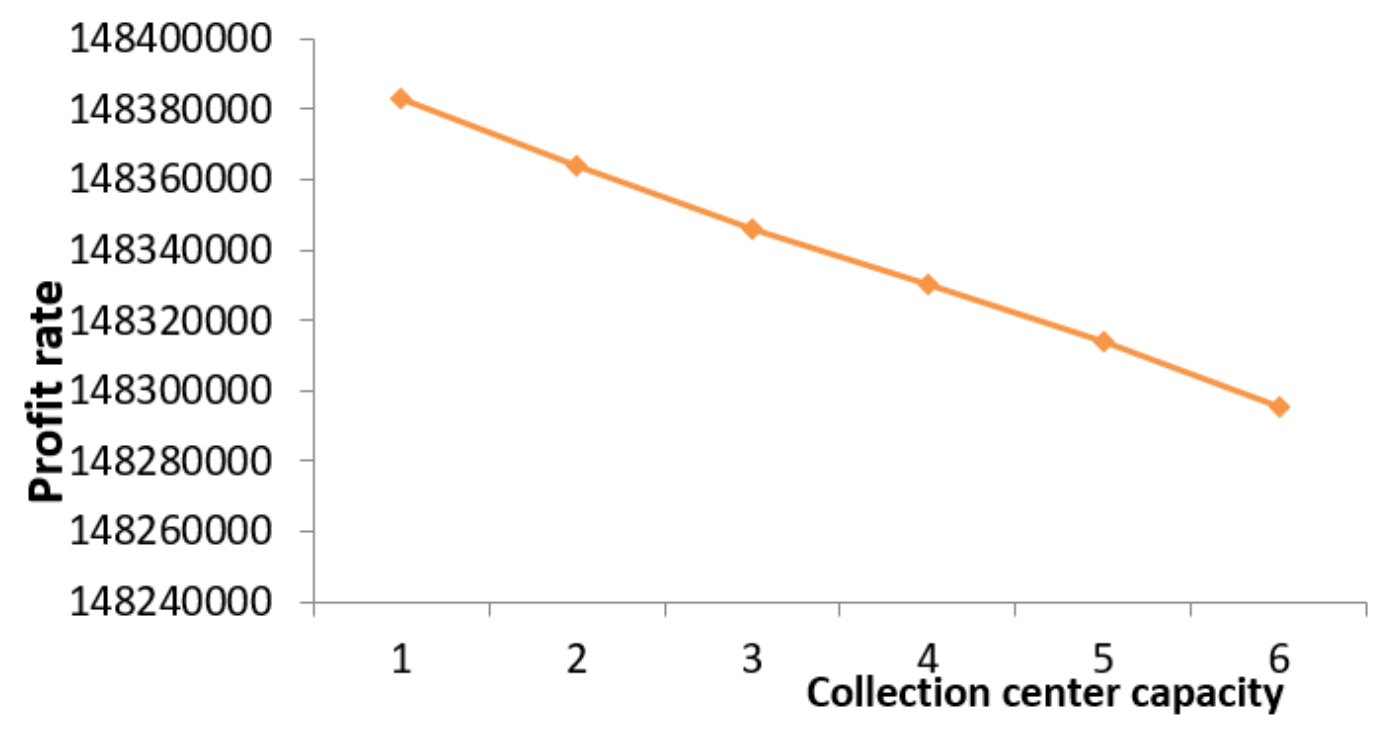

Figure 9

Profit analysis following the increase in the capacity of collection centers.

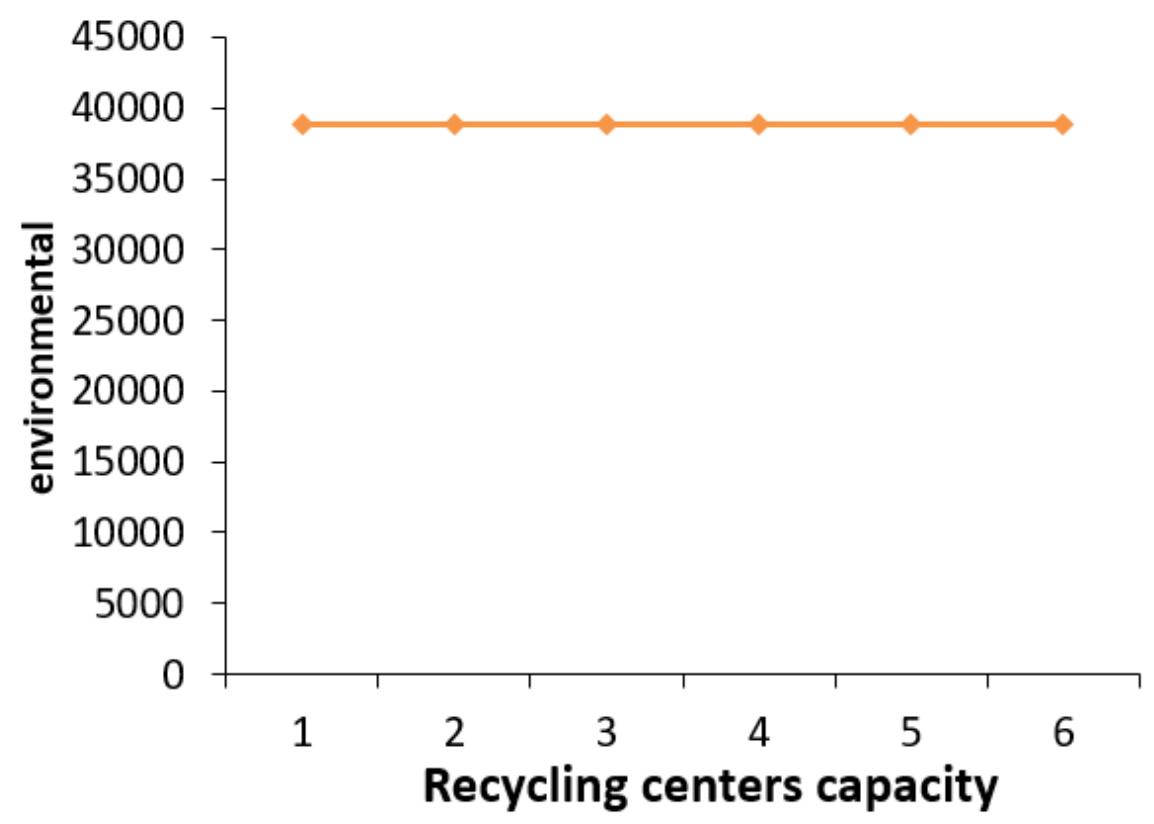

Figure 10

Analysis of environmental issues following the increase in the capacity of collection centers. 


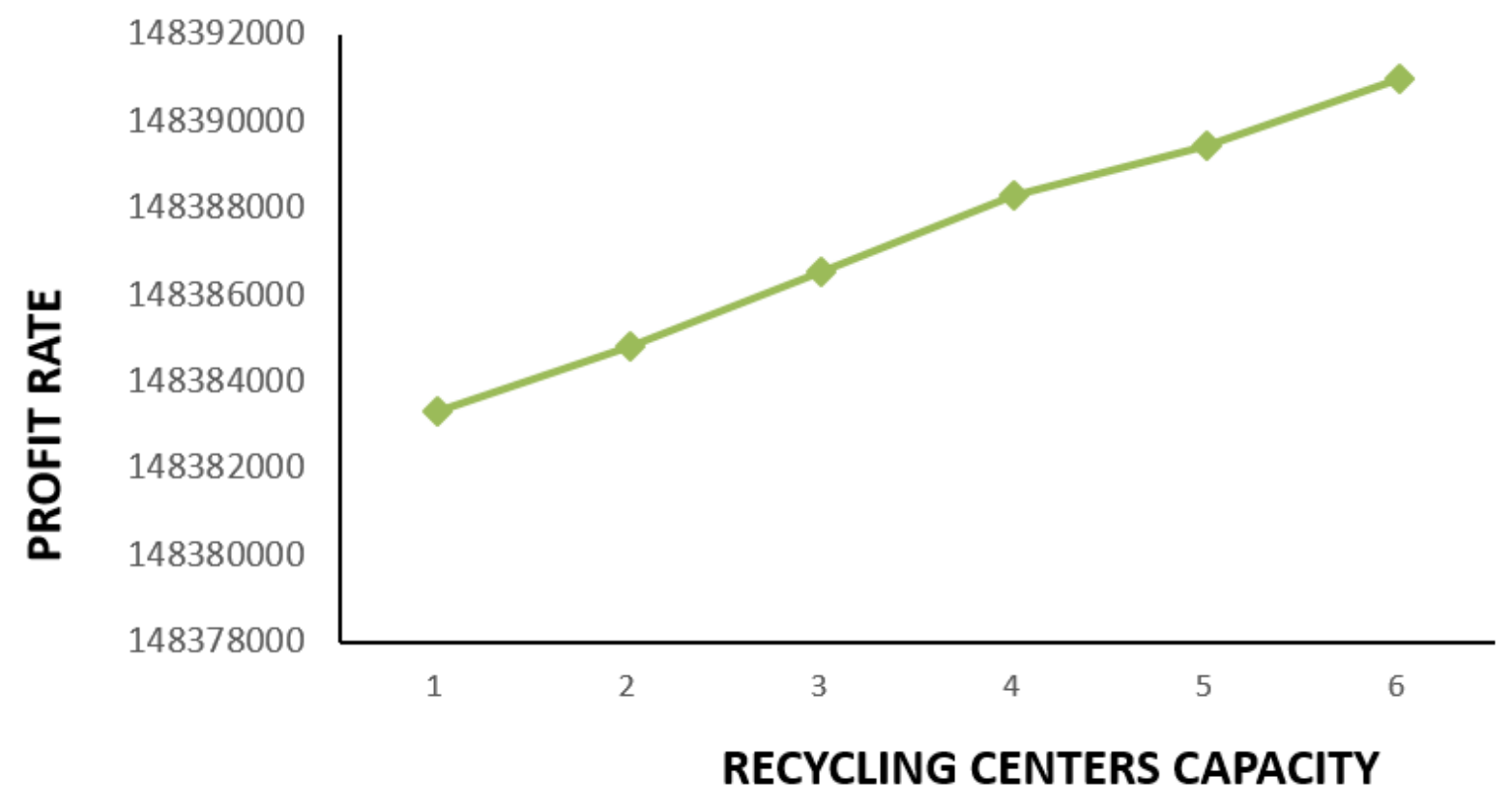

Figure 11

Profit analysis following the increase in the capacity of recycling centers.

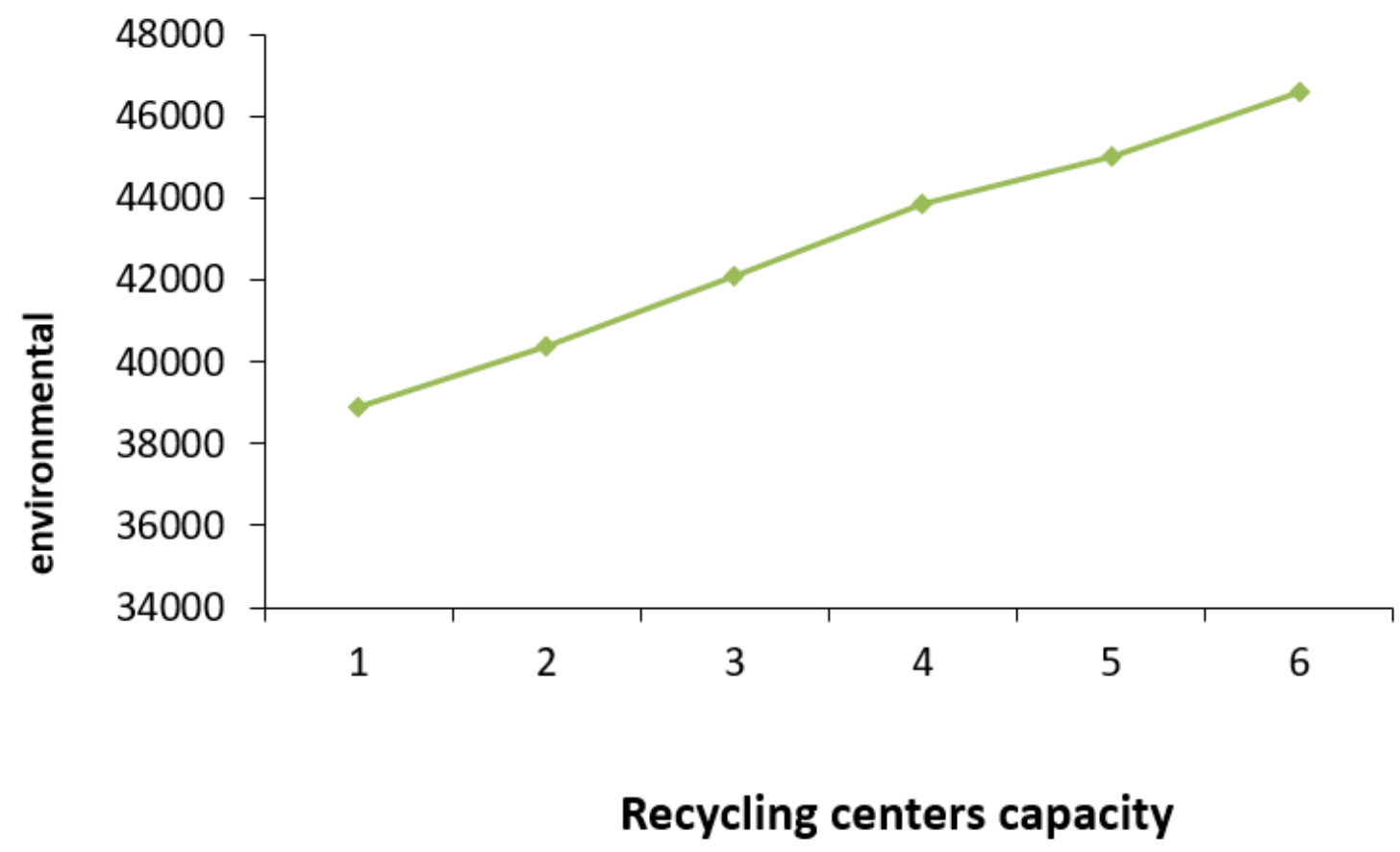

Figure 12

Analysis of environmental issues following the increase in the capacity of recycling centers. 